\title{
Replication of an Enterie Bovine Coronavirus in Intestinal Organ Cultures
}

\author{
By \\ JANice C. BridgeR ${ }^{1}$, E. O. CAUL ${ }^{2}$, and S. I. EgGLESTONE ${ }^{3}$ \\ 1 Institute for Research on Animal Diseases, \\ Compton, Berkshire, United Kingdom \\ 2 Public Health Laboratory, \\ Bristol, United Kingdom \\ 3 School of Environmental Sciences, Plymouth Polytechnic, \\ Plymouth, United Kingdom
}

With 9 Figures

Accepted October 18, 1977

\begin{abstract}
Summary
A coronavirus isolated in tracheal organ cultures from the faeces of a calf with diarrhoea readily multiplied on passage in intestinal organ cultures. Evidence for multiplication was obtained by the production of viral haemagglutinin in organ culture fluids and the presence of immunofluorescence and viral particles in the columnar epithelial cells of the villi. Thus virus multiplication was studied in vitro in the cell type in which it multiplies naturally.
\end{abstract}

\section{Introduction}

The cultivation in cell cultures of viruses associated with diarrhoea of man and animals has proved to be difficult or impossible $(1,6,9,10,12)$. However, organ cultures of intestinal tissue provide alternative in vitro culture systems which are similar to the tissues in which enteric viruses multiply naturally. They have been used for a number of human enteric viruses $(2,3,4,7,11)$ and animal enteric viruses (8). This paper describes the replication of the neonatal calf diarrhoea coronavirus in bovine intestinal organ cultures.

\section{Materials and Methods}

Source of Virus Inoculum

The bovine coronavirus ('The British Isolate') used in this study had been isolated from the faeces of a diarrhoeic calf by inoculation of a faecal filtrate into bovine tracheal organ culture (Bridger, Woode \& Meyling, to be published). The fluid from these primary isolation cultures had a haemagglutinating titre of $1 / 8$ and was stored at $-70^{\circ} \mathrm{C}$ before inoculation into gut organ cultures. 


\section{Preparation and Inoculation of Organ Cultures}

Organ cultures of upper small intestine from 4.5 to 6 month bovine foetuses were prepared as described previously (2). The maintenance medium was replenished every 24 hours. Cultures were infected 24 hours after preparation by dropping $0.05 \mathrm{ml}$ of inoculum onto each piece of tissue. After adsorption for 1 hour at $37^{\circ} \mathrm{C}$ the cultures were washed with $2.0 \mathrm{ml}$ of maintenance medium and $1.5 \mathrm{ml}$ of fresh medium was added to each dish. Control cultures received tracheal organ culture fluids from uninfected cultures.

\section{Examination of Inoculated Cultures}

Extracellular fluids and explants from infected and uninfected cultures were sampled at various time intervals. Extracellular fluids were examined for their haemagglutinating activity by the microtitre method using 1 per cent rat blood cells. In addition the fluids were centrifuged twice at $8000 \times g$ for 30 minutes followed by $100,000 \times g$ for 2 hours. The pellet was resuspended in a few drops of phosphate buffered saline, pH 7.2, and negatively stained with 2 per cent potassium phosphotungstate at $\mathrm{pH} 6.0$.

Immunofluorescence was carried out on sections of explants using either convalescent antiserum to the British isolate in an indirect test or, using a conjugated antiserum to the American bovine coronavirus (supplied by Dr. N. Zygraich of R.I.T., Rixensart, Belgium), in a direct test (Bridger, Woode \& Meyling, to be published).

Explants for histological examination were fixed in Bouin's solution and embedded in paraffin wax. Sections 5 um thick were cut and stained with haematoxylin and eosin.

Explants for electron microscopy were processed as described previously (2). Electron microscopic examination was carried out with either an AEI 801 or a Phillips 300 electron microscope.

\section{Results}

\section{Examination of Extracellular Fluids}

Haemagglutinating activity was first demonstrated 18 to 24 hours postinoculation. The highest titres of up to $1 / 128$ were obtained $24-48$ hours postinoculation and in one experiment remained at this level until 96 hours postinoculation when the experiment was terminated. These levels were not consistently maintained, as in another experiment with tissues from a different foetus, haemagglutinating activity began to fall at 48 hours post-inoculation. A further passage of the extracellular fluids produced similar amounts of haemagglutinating activity, indicating that infectious virus had been produced in the first passage in gut organ culture. No haemagglutinating activity was present in the control cultures.

Coronavirus particles (Figs. 1A and 1B) were seen in extracellular fluids taken at 18 to 96 hours post-inoculation but not at 6 and 12 hours post-inoculation. Virus particles were not present in control fluids. The particles were moderately pleomorphic and measured between $117-180 \mathrm{~nm}$ in diameter inclusive of an approximately $20 \mathrm{~nm}$ fringe. Commonly particles appeared to have an additional shorter fringe (Fig. $1 \mathrm{~A}$ arrowed) and some particles appeared to have lost many of their surface projections.

\section{Light Microscopic Examination of Inoculated Cultures}

No differences were apparent between infected and control cultures when unfixed cultures were examined. From the day on which cultures were prepared, there was a gradual loss of the regular pattern seen on the surface of fresh cultures. Variation was seen between explants from different foetuses in the degree of structure remaining after a given time in culture. 
Examination of histological sections confirmed the gradual decrease in villous length in both infected and control cultures. Specific viral lesions were not seen. Tissues which were fixed at the time the cultures were prepared had long finger-
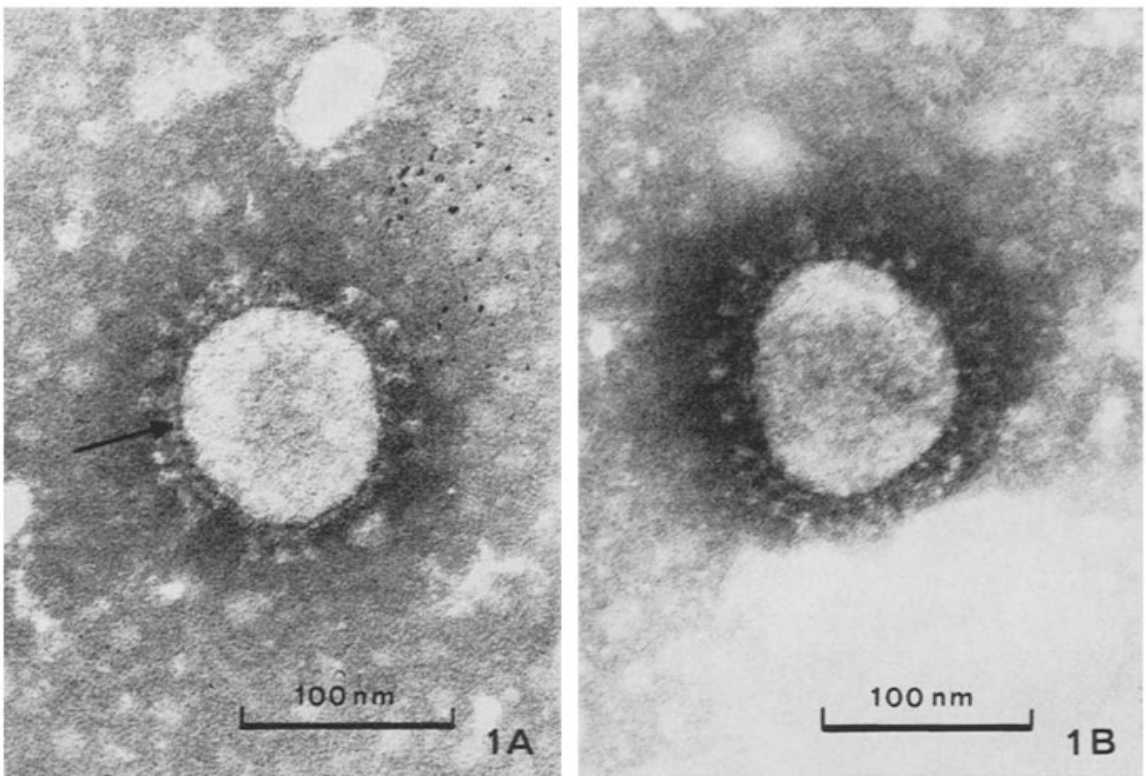

Fig. 1. Negatively stained coronavirus particles from extracellular organ culture fluids

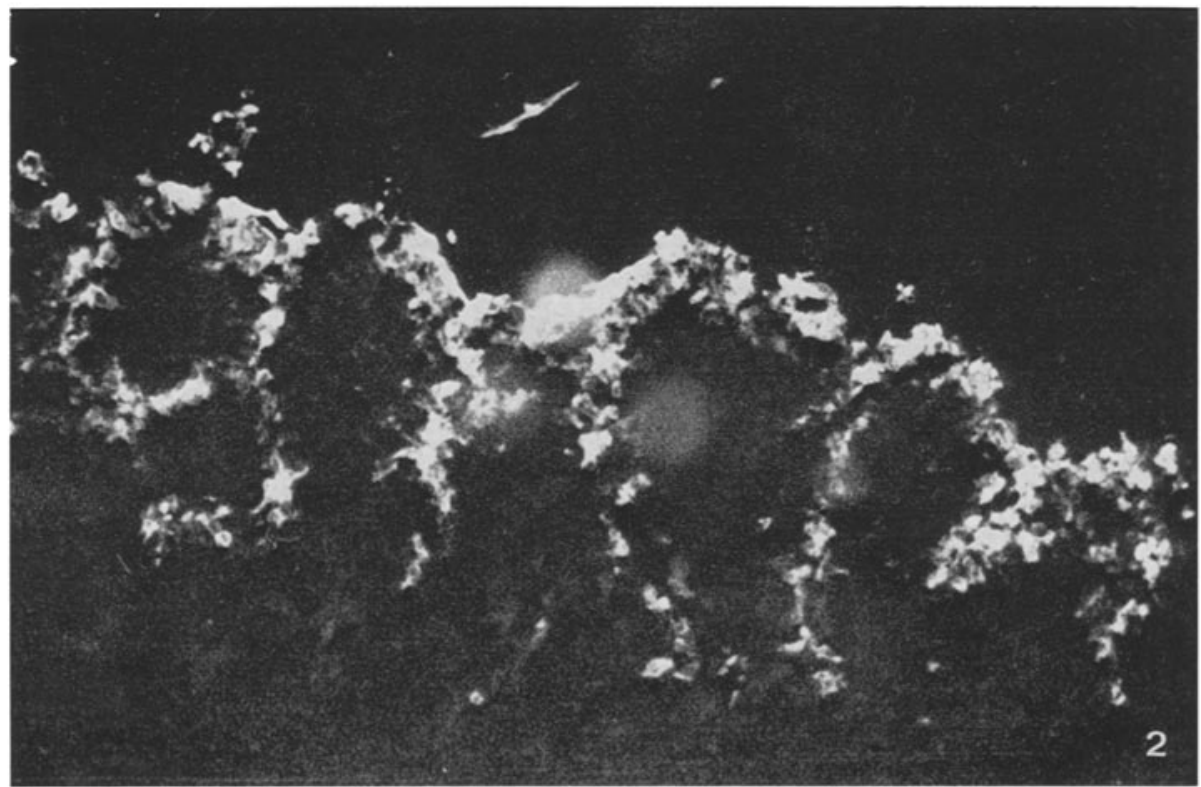

Fig. 2. Immunofluorescence of gut organ culture 24 hours after infection with bovine coronavirus. $\times 400$ 
like villi with a regularly arranged epithelium. After 24 hours in culture, at the time of inoculation, the villi were stunted but the columnar epithelium was still regularly arranged. Between 2 and 4 days in culture, depending on the cultures, the columnar epithelium lost its characteristic regular arrangement becoming irregular and disorganised.
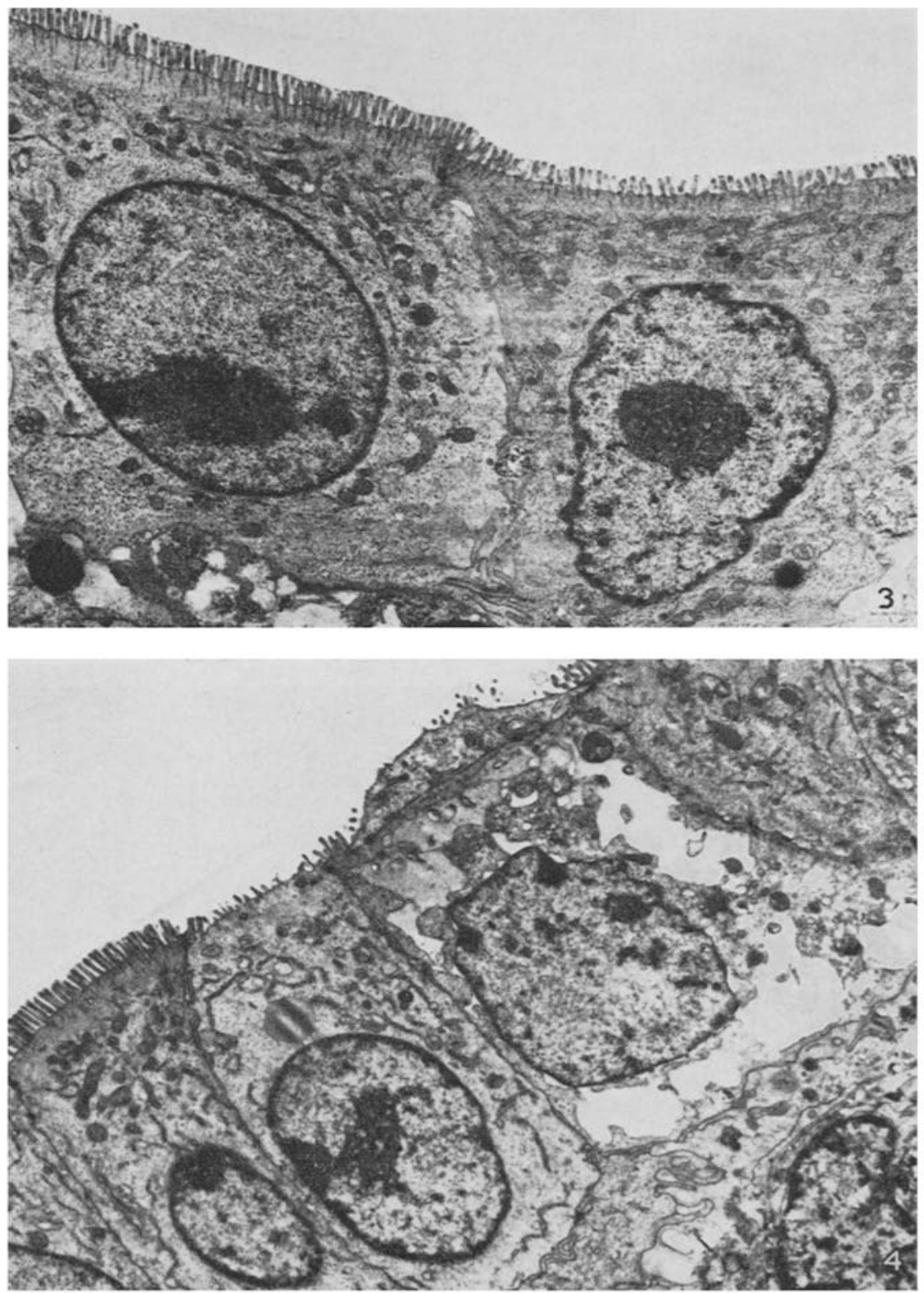

Fig. 3. Columnar epithelial cells from uninfected 24 hour control organ cultures. $\times 9000$ Fig. 4. Columnar epithelial cells infected with bovine coronavirus. Note the loss of the regular microvillous border. $\times 9000$ 
Immunofluorescence was detected solely in the columnar epithelial cells. It was first noted at 18 hours post-inoculation and had increased by 24 hours post-inoculation (Fig. 2). Some fluorescent cells were still present 42 and 72 hours
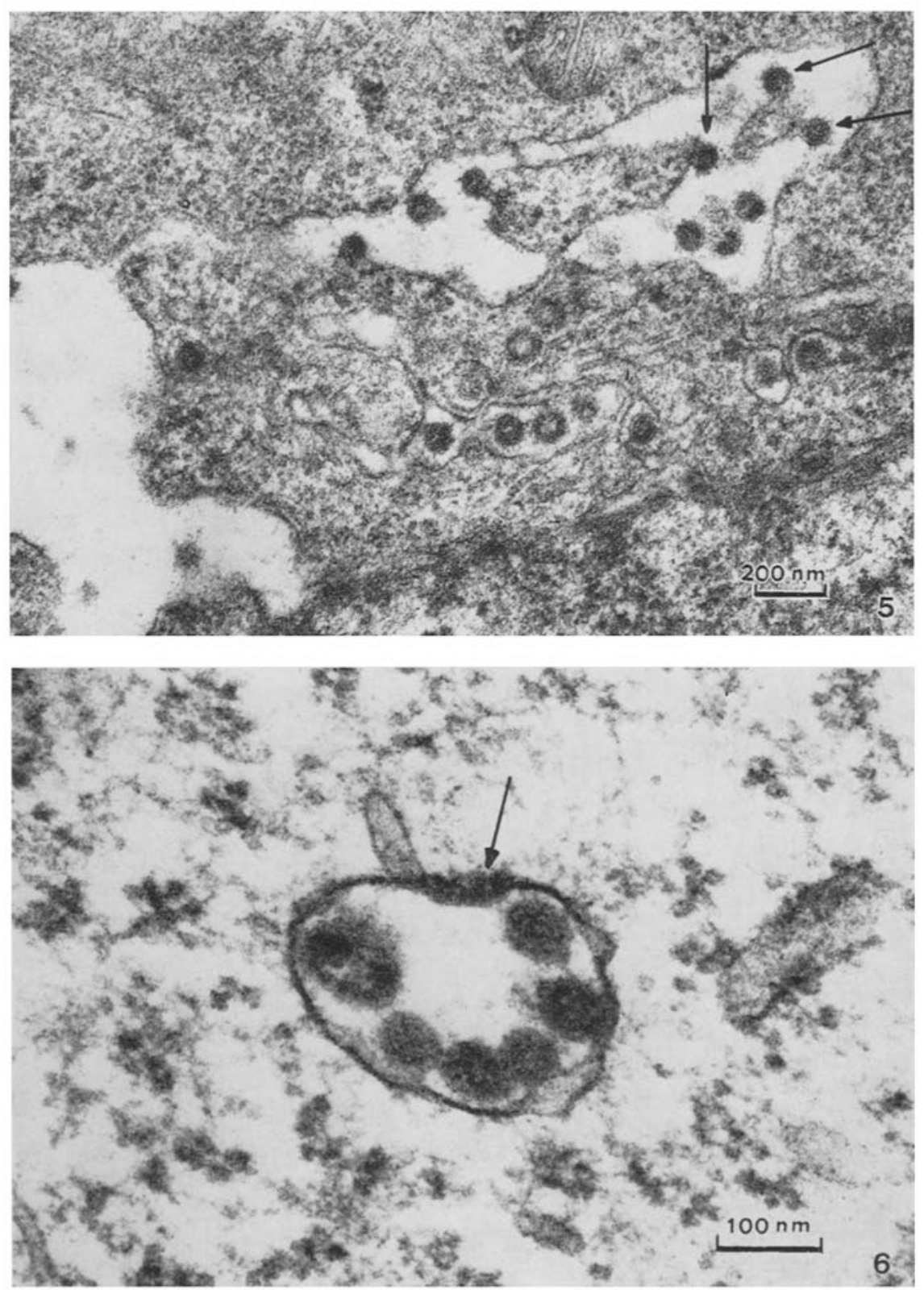

Fig. 5. Virus particles in cisternae of the smooth endoplasmic reticulum. Late stages of the budding process are shown. (arrows)

Fig. 6. Early stages in viral morphogenesis showing dense material in close apposition to a bulging membrane (arrowed) 
post-inoculation. Fluorescence was not seen in control cultures sampled at the same time. Sections stained by either the direct or indirect immunofluorescent test yielded the same pattern of immunofluorescent cells.
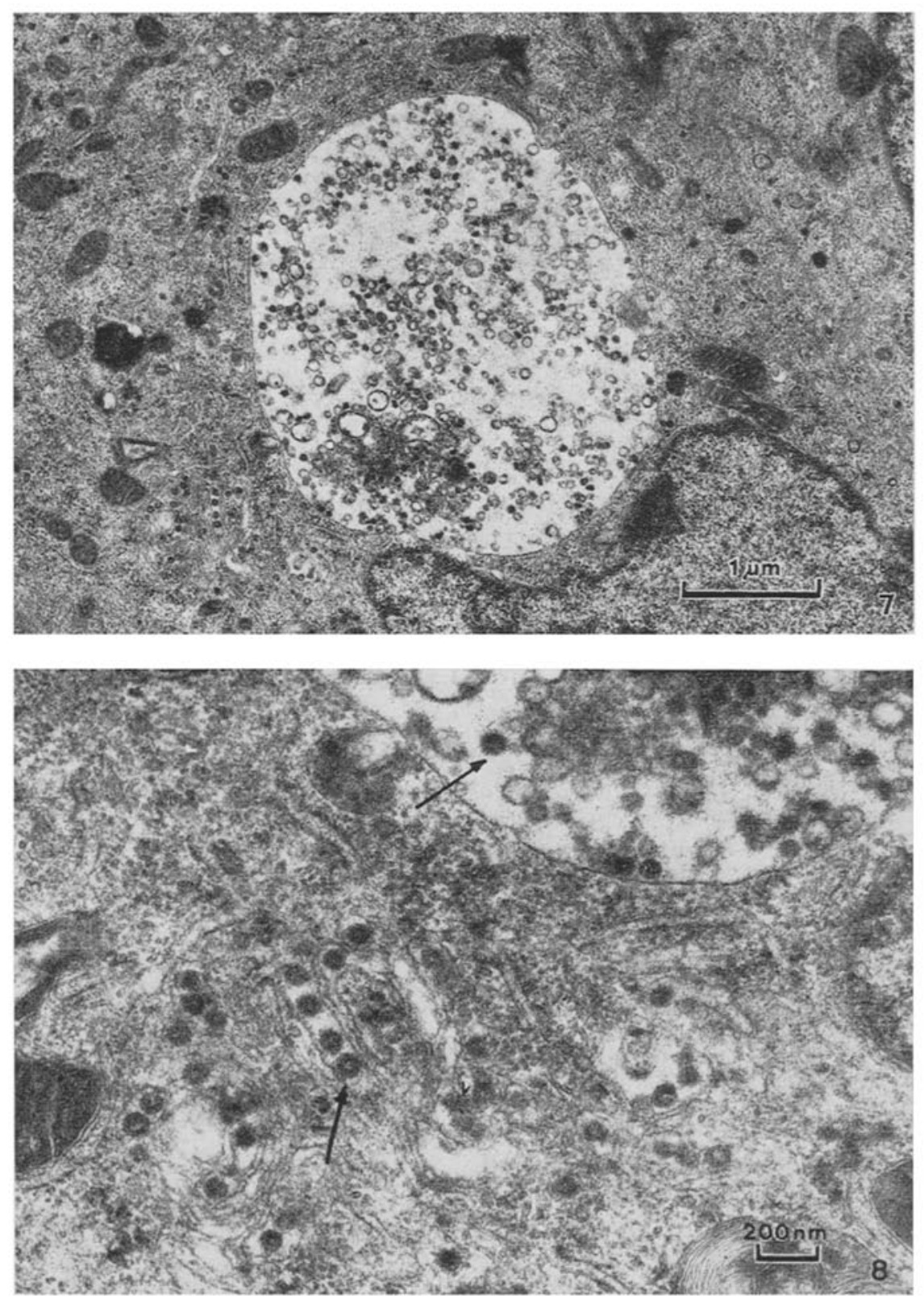

Fig. 7. Large perinuclear vacuole containing virus particles and degenerated cell organelles

Fig. 8. Comparison of vacuolar and endoplasmic reticulum virus particles (arrows) 


\section{Electron Microscopic Examination of Inoculated Cultures}

Explants were examined at 18 to 24 hours post-inoculation as this coincided with the peak of haemagglutinating and fluorescent activity. Columnar epithelial cells in uninfected control cultures (Fig. 3) had deep basal nuclei with regular microvillous borders and well defined terminal webs. Cell organelles appeared normal.

In contrast the infected cultures showed many cells which had lost the regular microvillous border (Fig. 4). The depth of the apical cytoplasm in the infected columnar epithelial cells was reduced and cell desquamation was not uncommon. No nuclear changes were observed throughout the study period. Many of these infected cells showed severe dilatation of the smooth endoplasmic reticulum and virus particles were seen in the cisternae and in cytoplasmic vesicles (Fig. 5). Various stages of virus morphogenesis were seen. An early stage with densely staining material in close apposition to a bulging membrane (Fig. 6, arrowed) and later stages of the budding process were also observed (Fig. 5, arrowed). Occasionally large perinuclear vacuoles containing virus particles and degenerated cell organelles were present (Fig. 7). Virus particles in the vacuoles were similar to those present in the eisternae of the smooth endoplasmic reticulum (Fig. 8, arrowed). Intracellular virus particles varied from electron dense spheres to particles having an electron translucent centre. Many of the latter particles had an electron dense ring separating the translucent centre from the double membrane. The particles had a mean diameter of $80 \mathrm{~nm}$. Extracellular virus particles adjacent to the microvilli were also present at the surface of the columnar epithelial cells (Fig. 9) but budding from the cell surface was not observed.

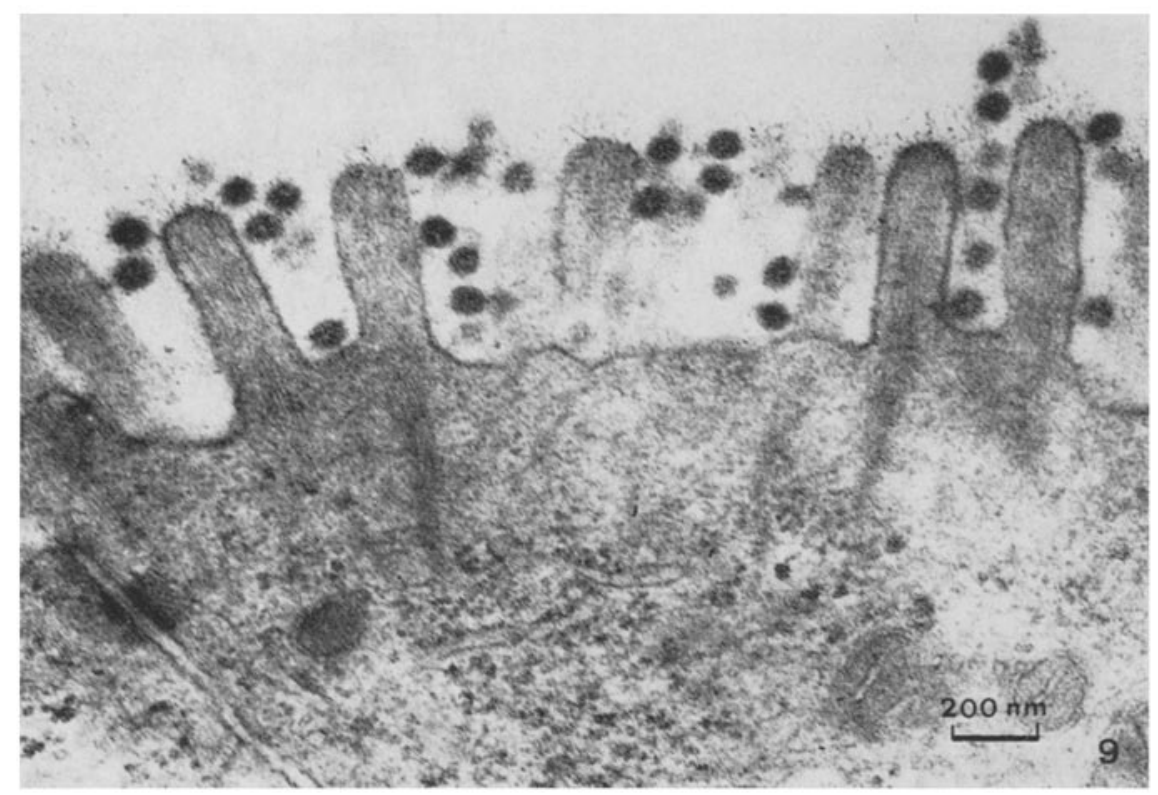

Fig. 9. Extracellular virus particles adjacent to the microvillous border 


\section{Diseussion}

Evidence for the replication of the bovine coronavirus in organ cultures of foetal bovine intestine was provided by the development of haemagglutinating activity, immunofluorescence and the appearance of ultrastructural changes consistent with the morphogenesis of coronaviruses. The development of haem. agglutinating activity and the appearance of fluorescence was closely linked to the presence of viral particles in both culture fluids and the columnar epithelial cells.

The ultrastructural changes seen in this model system were similar to those recently reported in a human intestinal system infected with a human enteric coronavirus (2). It is interesting to note the occurrence of large perinuclear vacuoles, which were also found in columnar epithelial cells infected with the human enteric coronavirus. These large vacuoles may result from the coalescence of smaller vesicles formed by the dilatation of the smooth endoplasmic reticulum. The large number of virus particles seen in these perinuclear vacuoles could be expected to produce perinuclear fluorescence. Such fluorescence has been observed in coronavirus infected cells by other workers. The observed ultrastructural changes reported in this study are consistent with the replication of known coronaviruses (5).

Negatively stained particles had the characteristic appearance of known coronaviruses, but a feature not observed with other coronaviruses examined by us was the apparent additional inner layer of projections. Further work is needed to elucidate the nature of these apparently different projections.

Differences in the duration of production of virus could be explained by variation in the viability and sensitivity of the organ cultures from different foetuses. The haemagglutination titre of virus produced in intestinal organ cultures was often four-fold higher than the highest titre obtained in either tracheal organ cultures or in cell cultures infected with the adapted strain of bovine coronavirus (Bridger, Woode \& Meyling, to be published). These results suggest that in the intestinal organ cultures virus replication is more efficient. It will be interesting to know whether this system is more sensitive for primary isolation.

Deterioration in the columnar epithelial cells over a number of days is not unusual. However, virus morphogenesis was studied over a period of 48 hours from preparation of the explants and over this time scale the columnar epithelial cells were maintained in good condition. This study shows that the bovine coronavirus multiplied readily in intestinal organ cultures and thus provides an in vitro model system for studying the replication of this virus in cells similar to those in which it multiplies naturally.

\section{Acknowledgments}

We thank Mr. L. J. Richardson, Meat Inspector at the Swindon abbattoir of Thos. Borthwick \& Sons, and Mr. L. Thomas for supplying the foetuses, Mr. C. R. Ashley and Mr. I. Jebbett for the photographic work and Mr. G. N. Woode for his help and advice.

\section{References}

1. CAUI, E. O., CLARKE, S. K. R.: Coronavirus propagated from patient with nonbacterial gastroenteritis. Lancet ii, $853-854$ (1975). 
2. CaUl, E. O., EGglestone, S. I.: Further studies on human enteric coronaviruses. Arch. Virol. 54, 107-117 (1977).

3. Dolin, R., Blacklow, N. R., Matmgren, R. A., Chañock, R. M. : Establishment of human foetal intestinal organ cultures for growth of viruses. J. inf. Dis. 122, $227-231(1970)$.

4. EgGinstone, S. I.: Laboratory investigation into the aetiology of non-bacterial gastroenteritis. Ph. D. Thesis, University of Bristol, 1968.

5. McIntosh, K.: Coronaviruses: A comparative review. Curr. Top. Microbiol. Immunol. 63, 85-129 (1974).

6. Merus, C. A., Statr, E. L., Rhodes, M. B., Twtehaus, M. J.: Neonatal calf diarrhea: propagation, attenuation and characteristics of a coronavirus-like agent. Amer. J. vet. Res. 34, $145-150$ (1973).

7. Rubenstein, D., Trreeld, D. A. J.: Growth of viruses in organ cultures of intestine. Brit. J. exp. Pathol. 51, 210-216 (1970).

8. Rubenstein, D., Tyrrelu, D. A. J., Derbyshire, J. B., Coluns, A. P.: Growth of porcine transmissible gastroenteritis (TGE) virus in organ cultures of pig tissue. Nature 227, $1348-1349(1970)$.

9. Thonnmul, T. S., Kalioa, A. R., WYatr, R. G., Kapikian, A. Z., Chavock, R. M.: Pattern of shedding of the Norwalk particle in stools during experimentally induced gastroenteritis in volunteers as determined by immune electron microscopy. J. inf. Dis. 132, $28-34(1975)$.

10. Woode, G. N., Bridgre, J. C.: Viral enteritis of calves. Vet. Rec. 96, 85-88 (1975).

11. Wyatt, R. G., Kapikian, A. Z., Thornhili, T. S., Sereno, M. M., Kim, H. W., CHANock, R. M. : In vitro cultivation in human foetal intestinal organ culture of a reovirus-like agent associated with non-bacterial gastroenteritis in infants and children. J. inf. Dis. 130, 523-528 (1974).

12. Wyatt, R. G., Ginl, V. W., Sereno, M. M., Kalica, A. R., Van Kirk, D. H., Chanock, R. M., KaptKran, A. Z.: Probable in vitro cultivation of human reoviruslike agent of infantile diarrhoea. Lancet i, 98-99 (1976).

Authors' address: Dr. JANICE C. Bridger, Institute for Research on Animal Diseases, Compton, Newbury, Berkshire, RG 16 0NN, U.K.

Received September 7, 1977 